\title{
Investigation of Psychophysiological and Subjective Effects of Long Working Hours - Do Age and Hearing Impairment Matter?
}

\author{
Verena Wagner-Hart|1,2* and K. Wolfgang Kallus ${ }^{1}$ \\ ${ }^{1}$ Department of Psychology, University of Graz, Graz, Austria, ${ }^{2}$ Faculty Industrial Technologies, Furtwangen University, \\ Campus Tuttlingen, Tuttlingen, Germany
}

Following current prognosis, demographic development raises expectations of an aging of the working population. Therefore, keeping employees healthy and strengthening their ability to work, becomes more and more important. When employees become older, dealing with age-related impairments of sensory functions, such as hearing impairment, is a central issue. Recent evidence suggests that negative effects that are associated with reduced hearing can have a strong impact at work. Especially under exhausting working situations such as working overtime hours, age and hearing impairment might influence employees' well-being. Until now, neither the problem of aged workers and

OPEN ACCESS

Edited by:

Gabriele Giorgi,

European University of Rome, Italy

Reviewed by:

Xiaoyang $\mathrm{Li}$,

Tsinghua University, China

M. Blake Hargrove,

Shippensburg University,

United States

*Correspondence:

Verena Wagner-Hartl

verena.wagner-hart@@

hs-furtwangen.de

Specialty section:

This article was submitted to

Organizational Psychology,

a section of the journal

Frontiers in Psychology

Received: 10 March 2017

Accepted: 28 November 2017

Published: 12 January 2018

Citation:

Wagner-HartI $V$ and Kallus KW

(2018) Investigation

of Psychophysiological and Subjective

Effects of Long Working Hours - Do

Age and Hearing Impairment Matter?

Front. Psychol. 8:2167.

doi: 10.3389/fpsyg.2017.02167 long working hours, nor the problem of hearing impairment and prolonged working time has been addressed explicitly. Therefore, a laboratory study was examined to answer the research question: Do age and hearing impairment have an impact on psychophysiological and subjective effects of long working hours. In total, 51 whitecollar workers, aged between 24 and 63 years, participated in the laboratory study. The results show no significant effects for age and hearing impairment on the intensity of subjective consequences (perceived recovery and fatigue, subjective emotional wellbeing and physical symptoms) of long working hours. However, the psychophysiological response (the saliva cortisol level) to long working hours differs significantly between hearing impaired and normal hearing employees. Interestingly, the results suggest that from a psychophysiological point of view long working hours were more demanding for normal hearing employees.

Keywords: long working hours, age, hearing impairment, cortisol, psychophysiology

\section{INTRODUCTION}

Until now, neither the problem of aged workers and long working hours, nor the problem of employees suffering from hearing impairment and prolonged working time has been addressed explicitly in a psychophysiological approach. Moreover, hearing impairment is one of the prominent symptoms of increasing age. The current paper addresses this interplay in a laboratory study.

\section{Age and Age-Related Impairments}

Demographic development raises expectations of an aging of the working population in the next years (e.g., World Health Organization [WHO], 1993; Statistik Austria, 2014), making it more 
and more important to keep employees healthy and strengthen their ability to work until they reach retirement-age. Demographic changes also require the working world to adapt to fewer available younger professionals; therefore elderly skilled employees have to be involved more in the working process (Müller, 2011). When employees get older, dealing with age-related impairments of sensory functions such as hearing impairment or vision-related impairments, is a central issue. While vision-related impairments are often corrected and the wearing of glasses is not a problem in society, unfortunately the same is not true for hearing impairment. People with hearing impairments often do not own a hearing aid. Reasons for this are for example that they feel that they hear well enough in most situations, hearing aids are uncomfortable or won't help them and that they would be embarrassed to wear hearing aids or they have not yet tested their hearing (Hougaard and Ruf, 2011). In addition, it also appears that, even if a hearing impaired person owns a hearing aid, hearing aids are sometimes not used regularly by their owners. So far, however, there has been little discussion about dealing with hearing impairment in the working world.

World Health Organization [WHO] (1993) defines aging workers as employees who are 45 years and older. According to World Health Organization [WHO] (2015a) data, over 5\% of the world's population (360 million people) has disabling hearing loss, which has been supported by a recent German study (Gablenz et al., 2017). In addition, the World Health Organization [WHO] (2015b) estimates that due to unsafe listening practices or rather unsafe or damaging levels of sounds (e.g., while listening to their audio devices, visiting clubs, bars or discotheques), 1.1 billion young people could be at risk of hearing loss. Considering this, research regarding reduced hearing capacity while people are employed or capable of employment becomes increasingly important. Hearing impairment has a significant impact on the quality of life of the person and was also found to be associated with reduced subjective emotional well-being and increased symptoms of depression (Scherer and Frisina, 1998; National Academy on an Aging Society, 1999; Mathers et al., 2000; Arlinger, 2003; Dalton et al., 2003; Monzani et al., 2008; Hawkins et al., 2012; Heffernan et al., 2016). Following Hawkins et al. (2012), self-reported hearing impairment influences not only the quality of life negatively, furthermore, the negative influence of hearing impairment seems to be stronger than other chronic medical problems like heart problems, diabetes, hypertension, or arthritis, which may also have an influence on early retirement. This view is supported by the National Academy on an Aging Society (1999) that reported a retirement rate of $18 \%$ for hearing-impaired, and a retirement rate of $12 \%$ for normal hearing American employees aged between 51 and 61 years. Analyses of data of the whole United States-working population have shown that $75 \%$ of the normal hearing compared to $67 \%$ of the hearing impaired working-age population was employed. However, a simple causal interpretation of these data is not possible.

Apart from the previously discussed impact on the quality of life of the concerned person itself, uncorrected reduced hearing also influences all persons that want to communicate with persons with hearing impairment (Jennings and Shaw, 2008;
Scarincia et al., 2009; Lemke and Scherpiet, 2015). One can easily imagine that this can have a strong impact at work. In addition, previous studies reported negative effects of hearing impairment on (job) performance caused by an impairment of speech comprehension, memory performance and selective attention (Boxtel et al., 2000; Pearman et al., 2000; Neijenhuis et al., 2004; Baskent et al., 2010; Lin et al., 2011; Rönnberg et al., 2011; Rudner et al., 2011; Nachtegaal et al., 2012; Lemke and Scherpiet, 2015; Wingfield et al., 2015; Frtusova and Phillips, 2016; Mudar and Husain, 2016). Furthermore, the information processing of hearing impaired is associated with significantly increased effort (Rabbitt, 1968; Kahneman, 1973; McCoy et al., 2005). To explain these findings, the so-called effortfulness hypothesis is used: Hence, to achieve the same perceptual performance as a normal hearing person, a person with hearing impairment must expend a higher performance effort (or more cognitive resources). This is followed by lower available process resources to decode the content and transfer it to short- and long-term memory. The question arises whether this supposed increase in performance effort of hearing impaired has an influence on their well-being or perceived exhaustion during working hours, especially under exhausting working situations such as working overtime hours.

\section{Long Working Hours}

According to article 2 of the Directive 2003/88/EC of the European Parliament and of the Council of 4 November 2003 concerning certain aspects of the organization of working time (European Parliament and Council of the European Union, 2003; p. L299/10), "working time" is defined as "any period during which the worker is working, at the employer's disposal and carrying out his activity or duties, in accordance with national laws and/or practice." "Rest period" is defined as "any period which is not working time." Generally, occupational scientists define "long working hours" as working hours that are beyond normal weekly hours of work. However, no consistent number of a defined limit of weekly hours can be found in literature beyond which additional hours are considered as long working hours. For example, Caruso et al. (2004) define long working hours as more than 40 working hours a week, whereas Dex et al. (1995) define them as more than $60 \mathrm{~h}$ of working. According to article 6 "Maximum weekly working time" of the Directive 2003/88/EC" (European Parliament and Council of the European Union, 2003; p. L299/11), "the average working time for each seven-day period, including overtime, does not exceed 48-hours" [article 6 (b)]. Therefore, this measure is also often used (e.g., Beswick and White, 2003; Kodz et al., 2003). An exact limit for working hours of a working day is not defined in the European Directive, however, a recovery time of $11 \mathrm{~h}$ a day is prescribed. Following the European Foundation for the Improvement of Living and Working Conditions (Eurofound, 2016) “overtime" is defined as "time worked in addition to hours worked during normal periods of work, and generally paid at higher rates than normal rates" (p. 5). Following this definition the normal weekly working hours have to be taken into account which can vary in different countries, sectors, and/or organizations (Eurofound, 2016). Also, overtime is not always paid or compensated by compensatory time off. In the United States, a differentiation between "exempt 
employees" and "non-exempt employees" do exist (Doyle, 2017). Following Doyle (2017) "the term 'exempt' means exempt from being paid overtime." Following the Overtime Pay Requirements of the Fair Labor Standards Act (FLSA; U.S. Department of Labor: Wage and Hour Division, 2012), "FLSA requires employers to pay covered non-exempt employees at least the federal minimum wage and overtime pay for all hours worked over 40 in a work week." An employee's workweek is defined as "a fixed and regularly recurring period of 168 -hours - seven consecutive 24-hour periods" (U.S. Department of Labor: Wage and Hour Division, 2008; p. 1). Following Dahlgren et al. (2006), long working hours are prevalent within today's working world, which has been supported by the results of the Foundation's Third European Survey on Working Conditions (15 EU Member States; Boisard et al., 2003) which showed that at least $17 \%$ of the fulltime employees are affected by long working hours, i.e., worked more than $45 \mathrm{~h}$ a week.

Previous research has shown that the organization of working time has not only an effect on health and social contacts/the social environment, but is also important from an economic point of view. For example, Nachreiner (2002) concludes that the risk of accidents increases exponentially after the seventh and eighth hour of overtime. This in turn results in increased subsequent costs such as remuneration in the event of sickness or increased insurance premiums. Furthermore, overtime increases the error rate, which from a long-term perspective, leads to an increase in economic costs. Other research groups also reported a negative impact on work performance and safety at work (e.g., Dembe et al., 2005; Folkard and Lombardi, 2006; Knauth, 2007). However, there are also studies that could not demonstrate a correlation between longer working hours and an increased risk of accidents (e.g., Trimpop et al., 2000; Akerstedt et al., 2002). Following Caruso's (2006) summary long working hours have direct impact on health and safety of employees. For example, long working hours are associated with insufficient sleep, as well as general fatigue. Furthermore, employees with long working hours show poorer performance in cognitive tasks, concentration and attention, and additionally, long working hours lead to unhealthy eating habits and a higher risk of long-term illnesses and injuries. On the other hand, not only the employees themselves are affected by long working hours, but also their family environment (Krenn and Hermann, 2004; Geurts et al., 2009). In addition to a subjectively perceived poorer well-being (Caruso et al., 2004), long working hours can have an impact on an increased risk of cardiovascular symptoms (Buell and Breslow, 1960; Uehata, 1991; Liu and Tanaka, 2002) and influence blood pressure negatively (elevated blood pressure through to hypertension; Iwasaki et al., 1998; Park et al., 2001; Rau and Triemer, 2004; Su et al., 2008). In addition, Park et al. (2001) showed an association with lowered heart rate variability. Also, diseases of the musculoskeletal system increase with longer working hours (Raediker et al., 2006; Trinkoff et al., 2006). Furthermore, a relationship between metabolic disorders such as diabetes mellitus or the metabolic syndrome and long working hours was shown (Sparks et al., 1997; Spurgeon et al., 1997; Violanti et al., 2009). The question arises whether a critical interplay between age and age-related impairments like hearing impairment and effects of long working hours do exist. Therefore, age differences regarding long working hours are of importance. Here, a trend reversal seems to take place. Whereas in 1979, in the United States the group of employees with the longest working hours were between 25 and 34 years old and employees aged between 55 and 64 years worked far less, this trend had been reversed in 2006 (Kuhn and Lozano, 2006). Very similar conclusions were shown by Beswick and White (2003) for working hours in the United Kingdom, and the results of the Foundation's Third European Survey on Working Conditions (15 EU Member States; Boisard et al., 2003) additionally indicate that older employees do not work shorter hours than younger employees. Considering all of this evidence, it seems that studies with an age-specific point of view on the effect of long working hours, becomes more and more important. Especially, due to the expectation that the occurrence of aftereffects of long working hours will manifest themselves as problems with advanced age. For this reason, our study focuses not only on the impact of reduced hearing capacity but also on age.

\section{Recovery}

In addition to previously described general effects of age, age related impairments and long working hours, also the interplay with employees' recovery, is of interest. Following Sonnentag et al. (2008, p. 675) "recovery is an important concept in the context of job stress and strain." Recovery is required in order to compensate negative consequences of strain, such as mental fatigue, and to restore conditions to achieve optimum performance (Allmer, 1996). Kallus and Erdmann (1994) define recovery as dynamic psychophysical process. This includes basic biological regulation processes at different physiological levels as well as mental regulation and control processes, up to complex emotions, cognitions, actions, and social interactions. Following Kellmann and Kallus (2000, p. 210) recovery is characterized as follows: "recovery is a process in time, is related to the type of and duration of stress, depends on a reduction of, a change of, or a break from stress, is individually specific and depends on individual appraisal, ends when the psychophysical state of restored efficiency and homeostatic balance is reached, includes purposeful action (active recovery), as well as automated psychological and biological processes restoring the initial state (passive recovery) and can be described on various levels (e.g., physiological level, psychological level, social level, socio-cultural level, environmental level). Furthermore, recovery processes can be displayed in various organismic subsystems, various subprocesses of recovery can be dissociated and recovery is closely tied to boundary conditions (e.g., sleep, social contact, etc.)." Kallus (2016, p. 42) suggests that these characteristics show "that recovery is much more than eliminating fatigue or restarting the system."

According to Nachtegaal et al. (2009) there is a significant correlation between hearing status and need for recovery after work in a way that a higher need of recovery after work is reported by people with poorer than by people with better hearing status. Furthermore, older employees seem to have a stronger need of recovery than younger employees (e.g., Jansen et al., 2002; Kiss et al., 2008). In addition, Sonnentag and Zijlstra (2006) reported 
a positive relationship between the amount of overtime work and the need for recovery. From our point of view, there is a gap in literature regarding the combination of these variables and their influence on employees' recovery and well-being. Our study addresses this gap in literature and therefore focusses on hearing capacity and age under exhausting working situations such as working overtime hour's, respectively, long working hours.

\section{Endocrine Stress Parameters}

As mentioned before, long working hours can provoke stress. On the one hand, stress can be assessed subjectively (e.g., questionnaires). On the other hand, psychophysiological parameters, such as cardiovascular activity and responses of the endocrine system are able to show stress or rather arousal of an individual from an objective point of view. Regarding the endocrine system, mental, emotional, and physical stress can lead to an increase in cortisol levels within minutes. This is one of the reasons why the psychophysiological parameter cortisol is applied as one of the most important stress hormones besides the catecholamines noradrenaline and adrenaline (Kirschbaum, 1991). Cortisol is controlled by the hypothalamic-pituitary-adrenal axis (HPA axis). If the HPA axis is dysregulated, a hyper- or hyposecretion of cortisol is possible (Pruessner et al., 1997). Cortisol is a steroid hormone produced by the adrenal cortex and affects many physiological systems. It increases the carbohydrate-, fat-, and protein-metabolism and enables a rapid physical performance enhancement and, in addition, affects immune functions. Thus, the organism is able to adequately respond to stress (Selye, 1936). Cortisol is measured at different measurement times in the presented study (see Materials and Methods section). Following a circadian rhythm, the cortisol level is typically high in the morning after waking up, showing an increase by approximately $50-60 \%$ in the first $30-45 \mathrm{~min}$ after awakening, and decreases rapidly in the first hours thereafter. During the day the cortisol level decreases slowly until it reaches its lowest level around midnight (Pruessner et al., 1997; Wust et al., 2000). The circadian rhythm is very stable over age (healthy persons). Adam et al. (2006) reported no significant effects of age on the wakeup cortisol level.

Jahncke and Halin (2012) used salivary cortisol to investigate differences between hearing impaired and normal hearing participants during a simulated open-plan office working situation. The results show a tendency toward higher stress levels during noise exposure of $60 \mathrm{~L}_{\text {Aeq }}$, for hearing impaired compared to normal hearing participants. The authors assume that this effect is possibly caused by the fact that hearing impaired are being more noise sensitive and distracted by noise than normal hearing individuals. Controversial results for the relationship between (long) working hours and cortisol levels are shown in literature. Dahlgren et al. (2006) compared a normal working week ( $8 \mathrm{~h} /$ day / 40 -h workweek) to a week with long working hours $(12 \mathrm{~h} /$ day / $60 \mathrm{~h} /$ week). No significant main effect of overtime was shown for the salivary cortisol data of the participants but a trend toward an interaction effect for the morning values: An increase at the end of the working week with long working hours compared to the normal working week was reported. Due to the relatively small sample size (18 office workers) the authors suggest to interpret these data with caution. On the other hand, Persson et al. (2003) were not able to show a significant association between working hours and salivary cortisol (two working-hour groups: $8 \mathrm{~h} / 5$ days, i.e., $40 \mathrm{~h}$ a week; $12 \mathrm{~h} / 7$ days, i.e., $84 \mathrm{~h}$ a week), which was confirmed in a longitudinal study by Steptoe et al. (1998). Further, Marchand et al. (2012) suggest that the effect of working hours on the cortisol level is non-linear and therefore only becomes visible after a time period of more than two working days. Besides this, a negative correlation between job strain and cortisol occurred in the study of Steptoe et al. (1998). However, Steptoe et al. (2000) showed a higher cortisol level of people that experienced a highlevel of job strain compared to people that experienced low job strain. This is in line with other research groups that showed a correlation between workload and cortisol awakening response (CAR) and between workload and a stronger increase of the cortisol level after awakening (e.g., Kunz-Ebrecht et al., 2004; Eller et al., 2006). To sum it up, controversial results for the relationship between working hours and cortisol level are shown in literature, while there is more consensus on the relationship between job strain, workload, and cortisol level.

Whereas effects of gender, smoking status, alcohol consumption or job support were often investigated in the different studies, the combined effects of long working hours, age and hearing impairment were not investigated as important variables - at least not in a psychophysiological approach. If age was mentioned in the studies, the authors report that age was controlled within their samples. Our study extends past research on long working hours by including age as variable of interest. Therefore, the aim of the study presented in this paper was to examine if age and hearing impairment, do have an impact on psychophysiological and subjective effects of long working hours. Accordingly, the following research question should be answered: Do age and hearing impairment have an impact on psychophysiological and subjective effects of long working hours?

\section{MATERIALS AND METHODS}

A laboratory study with repeated measurement design was chosen. The study was conducted in an experimental laboratory of the department of psychology at the University of Graz, Austria.

\section{Participants}

In total 61 employees (white-collar workers) participated in the laboratory study. Salivary cortisol measurements of 51 of them were available. Loss of salivary cortisol data of 10 participants was due to not analyzable samples or the non-willingness to participate in this psychophysiological measurement. Therefore, for analyses presented within this paper, the final sample consists of 51 white-collar workers, aged between 24 and 63 years $(M=39.69, S D=11.62)$. Following the definition of World Health Organization [WHO] (1993) whereas aging workers are defined as workers who are aged 45 years and older, 22 participants (43.14\%) belong to the group of aging workers or 
older workers. $50.98 \%$ of the participants were female and $49.02 \%$ were male. All of them performed their work primarily in office workplaces. $7.84 \%$ of the participants were self-employed, $21.57 \%$ have a leadership position. $54.90 \%$ of the participants reported an average overtime of $1-5 \mathrm{~h} /$ week in the last 3 months before they participated in the study, $25.50 \%$ of $6-10 \mathrm{~h} /$ week, $9.80 \%$ of 11 and more hours per week and $9.80 \%$ did not work overtime hours in the last 3 months. None of the participants owns a hearing aid. Participants' hearing abilities were screened by audiometry. Their hearing loss measured by audiometry ranged for the worse hearing ear from 2.50 to 46.25 pure tone average (PTA) dB HL $(M=11.47, S D=7.06)$. The criterion to be included in the hearing impaired group was a worse ear hearing loss of $15 \mathrm{~dB}$ or more on a minimum of two out of the four (speech relevant) frequencies $0.5,1,2$, and $4 \mathrm{kHz}$. Following the criterion, 21 participants (female: 12 , male: 9 ; age: $M=45.67, S D=12.12$ ) were included in the hearing impaired group, 30 participants (female: 14, male: 16; age: $M=35.50, S D=9.34$ ) were included in the normal hearing group. The unequal distribution regarding age of the two groups, $t(49)=-3.38, p=0.001$, can be explained by the natural aging process of auditory functions. To control possible effects of the commute of the participants from their workplace to the experimental laboratory, a baseline measurement of all study variables was performed at the beginning of the experimental session. Regarding the study variables, no significant differences at the baseline measurement were found for the two different hearing groups. Therefore, the effects can be attributed to the study manipulation. In addition the hearing groups do not differ significantly regarding average overtime per week in the last 3 months nor regarding the number of overtime hours in the current working week in which they participated in the study.

The participants were recruited via the homepage of the University of Graz, short communications in regional newspapers and notices that were posted at notice boards in different companies, supermarkets, universities, medical practices of otolaryngologist and hearing aid acousticians. All participants received 65 Euro to refund their transportation costs and as incentive for their participation. Informed written consent was obtained from all participants.

\section{Study Design, Materials, and Procedure}

To answer the research question if age and hearing impairment do have an impact on psychophysiological and subjective effects of long working hours, a repeated measurement design was chosen for the laboratory study. Hearing impairment [normal hearing employees, hearing impaired employees (worse ear hearing loss of $15 \mathrm{~dB}$ or more on a minimum of two out of the four (speech relevant) frequencies $0.5,1,2$, and $4 \mathrm{kHz}$ )] was defined as independent variable and age of the participants was included as covariate in the analyses. Five different dependent variables (DV) were measured: DV1: perceived recovery, DV2: perceived fatigue, DV3: subjective emotional well-being, DV4: subjective physical symptoms, DV5: cortisol level.

Time of measurement was used as repeated measurement factor. Overall, each study participant participated in the study for two consecutive days. To participate in the study, each study participant came to our laboratory of the University of Graz directly after his/her regular working hours. On both days the participants had to work in the study (performance tests, etc. - Vienna Test System, Schuhfried GmbH) at least three additional hours to simulate a situation of long working hours (day 1: three to max. five additional hours; day 2: three additional hours). The examination procedure is based on the "Grazer fatigue paradigm" (Deixelberger-Fritz et al., 2003), which is well-established for experimental studies of stress, and especially fatigue. With the choice of a long period of execution and carrying out the investigation after a normal working day of the participants, the approach emphasizes the results of Healy et al. (2004). These results suggest that a reliable measurement of fatigue may only be possible after a working duration of at least $1-2 \mathrm{~h}$ on top of the usual working hours per day.

Two measurement times were analyzed for all dependent variables (subjective measures and saliva cortisol level): (1) at the end of the study session of the first day of the laboratory study, and (2) at the end of the study session of the second day of the laboratory study. In addition, a third measurement time was available for saliva cortisol level: the waking cortisol level on the second day of the study.

\section{Pure-Tone Audiometry}

Pure-tone audiometry was conducted in the beginning of the first study session, using a standard Audiometer (Micromate 304, Madsen Electronics). Following the WHO (Mathers et al., 2000) and the European Working Group on Genetics of Hearing Impairment [EUWG] (1996) hearing loss was measured by audiometry and calculated on the basis of the pure-tone average (PTA) of hearing thresholds at $0.5,1,2$, and $4 \mathrm{kHz}$.

\section{Saliva Cortisol}

To measure cortisol in saliva, saliva samples were obtained with Salivette tubes (Sarstedt) at three measurement times during the study: (1) at the end of the study session of the first day of the laboratory study, (2) the waking cortisol level on the second day of the study and (3) at the end of the study session of the second day of the study. Measurement time (1) and (3) were instructed by the investigator. Only measurement time (2), the waking cortisol level had to be carried out independently by the study participants. The participants were instructed to take the saliva sample $30 \mathrm{~min}$ after waking up in the morning and not to brush their teeth, eat, drink, smoke, or do physically demanding activities before providing the saliva sample. The exact time had to be recorded in a protocol. The saliva samples were analyzed at the Technical University of Dresden (Department of Psychology, Biopsychology, Prof. Dr. Kirschbaum) by a professional blind to the experimental conditions. There, the samples were centrifuged for $5 \mathrm{~min}$ at a rotation speed of 3,000 rotations/min. The cortisol concentration was measured using cortisol luminescence immunoassay (CLIA) with a high sensitivity of $0.16 \mathrm{ng} / \mathrm{ml}$.

\section{Subjective Emotional Well-being}

For the measurement of the current subjective emotional wellbeing a category adjective checklist (German version) consisting 
of 24 items (BSKE-24-ak) from Janke et al. (1986) was used. The BSKE is based on the German Adjective Checklist EWL (Janke and Debus, 1978). It assesses the current emotional state multidimensional. The eight different sub-dimensions of the BSKE are: balance, lifted mood, activation, excitement, irritability, anxiety/sadness, de-activation, and extraversion. Responses are based on a seven-point scale ranging from 0 (not at all) to 6 (most intensive). Reliabilities are given as 0.70 to 0.90 (Janke and Debus, 1978). Example item: "Feeling of emotional well-being (e.g., pleasant, satisfied) ... 0 (not at all) to 6 (most intensive)." Two measurement times were analyzed: (1) at the end of the study session of the first day of the study, and (2) at the end of the study session of the second day of the laboratory study.

\section{Subjective Evaluation of Perceived Recovery}

For the measurement of perceived recovery, the German version of the scale for perceived recovery (SwE) from Kallus and Eibel (2007) was used. Responses are based on 7 descriptive categories and 51 fine adjustments from 0 (not at all recovered) to 51 (extremely strong recovered) following the method of the category subdivision approach (Heller, 1985). Participants have to assess their current perceived recovery by following a two-step procedure: First participants have to scale their perceived recovery in one of seven descriptive categories ("not at all recovered" to "extremely strong recovered") and afterward, they have to select one out of 10 levels within the initially selected descriptive category (except for the two extrema not at all/extremely strong recovered, where only one level is available). Two measurement times were analyzed: (1) at the end of the study session of the first day of the study, and (2) at the end of the study session of the second day of the laboratory study.

\section{Subjective Evaluation of Perceived Fatigue}

For the measurement of perceived fatigue, the German version of the scale for perceived fatigue (SwM) from Kallus and Eibel (2008) was used. Responses are based on 7 descriptive categories and 51 fine adjustments from 0 (not at all fatigued) to 51 (extremely strong fatigued) following the method of the category subdivision approach (Heller, 1985). Participants have to assess their current perceived fatigue by following a two-step procedure: First participants have to scale their perceived fatigue in one of seven descriptive categories ("not at all fatigued" to "extremely strong fatigued") and afterward, they have to select one out of ten levels within the initially selected descriptive category (except for the two extrema not at all/extremely strong fatigued, were only one level is available). Two measurement times were analyzed: (1) at the end of the study session of the first day of the study, and (2) at the end of the study session of the second day of the laboratory study.

\section{Subjective Physical Symptoms}

For the measurement of the current subjective physical symptoms the 24-item German version of the multidimensional physical symptom list (MKSL-24-ak) from Erdmann and Janke (1994) was used. The seven different sub-dimensions of the MKSL are: pain; nausea, cholinergic symptoms; vegetative symptoms; adrenergic symptoms; general physical relaxation; palpitations; flushing, sensation of heat. Responses are based on a seven-point scale ranging from 0 (not at all) to 6 (most intensive). Reliabilities are given as 0.30 to 0.70 (Krejcza, 2006). Example item: "Feeling physical weakness or physical exhaustion ... 0 (not at all) to 6 (most intensive)." Two measurement times were analyzed: (1) at the end of the study session of the first day of the study, and (2) at the end of the study session of the second day of the laboratory study.

\section{Statistical Analyses}

The statistical analyses of the data were conducted using the software SPSS for Windows. MANCOVAs and ANCOVAs with repeated measures were used as statistical procedure. The analyses were based on a significance level of $5 \%$.

\section{RESULTS}

\section{Subjective Emotional Well-being}

The results of a MANCOVA with repeated measures showed a significant effect of the covariate age. Following the univariate tests for the eight sub-dimensions, this effect reaches the level of significance only for the sub-dimension irritability, $F(1,48)=5.42, p=0.024, \eta_{\mathrm{p}}^{2}=0.101$. All other effects do not reach the 5\%-level of significance. The coefficients are shown in Table 1. Regarding the sub-dimension irritability, correlations between the age of the participants and their reported irritability at the end of the study sessions show that irritability tends to

TABLE 1 | Results of the ANCOVAs and MANCOVAs.

\begin{tabular}{lccccr}
\hline \multicolumn{1}{c}{$\boldsymbol{F}$} & $\boldsymbol{d} \boldsymbol{f}$ & $\boldsymbol{d f}_{\text {Error }}$ & $\boldsymbol{p}$ & $\boldsymbol{\eta}_{\mathbf{p}}^{2}$ \\
\hline Subjective emotional well-being & & & & \\
Age & 2.83 & 8 & 41 & 0.013 & 0.356 \\
Hearing impairment & 1.18 & 8 & 41 & 0.336 & 0.187 \\
Time & 1.08 & 8 & 41 & 0.396 & 0.174 \\
Time $\times$ hearing impairment & 0.51 & 8 & 41 & 0.842 & 0.091 \\
Subjective evaluation of perceived recovery & & & \\
Age & 0.10 & 1 & 48 & 0.752 & 0.002 \\
Hearing impairment & 0.11 & 1 & 48 & 0.747 & 0.002 \\
Time & 0.17 & 1 & 48 & 0.680 & 0.004 \\
Time $\times$ hearing impairment & 0.33 & 1 & 48 & 0.912 & $<0.001$ \\
Subjective evaluation of perceived fatigue & & & \\
Age & 0.31 & 1 & 46 & 0.584 & 0.007 \\
Hearing impairment & 0.01 & 1 & 46 & 0.949 & $<0.001$ \\
Time & 0.07 & 1 & 46 & 0.796 & 0.001 \\
Time $\times$ hearing impairment & 0.01 & 1 & 46 & 0.958 & $<0.001$ \\
Subjective physical symptoms & & & & \\
Age & 0.31 & 7 & 42 & 0.945 & 0.049 \\
Hearing impairment & 0.30 & 7 & 42 & 0.952 & 0.047 \\
Time & 1.00 & 7 & 42 & 0.444 & 0.143 \\
Time $\times$ hearing impairment & 1.77 & 7 & 42 & 0.120 & 0.227 \\
Cortisol level & & & & & \\
Age & 6.04 & 1 & 48 & 0.018 & 0.112 \\
Hearing impairment & 4.76 & 1 & 48 & 0.034 & 0.090 \\
Time & 0.50 & 1.06 & 51.03 & 0.496 & 0.010 \\
Time $\times$ hearing impairment & 3.52 & 1.06 & 51.03 & 0.064 & 0.068
\end{tabular}


decrease with age [t1: $r=-0.227, p=0.109$; $\mathrm{t} 2: r=-0.233$, $p=0.100$; partial correlation (controlled variable: hearing impairment): $\mathrm{t} 1: r=-0.286, p=0.044 ; \mathrm{t} 2: r=-0.300$, $p=0.035]$.

\section{Subjective Evaluation of Perceived Recovery/Fatigue}

Hearing impairment does not have a significant effect neither on the perceived recovery of the participants nor on their perceived fatigue at the end of the study sessions. Also, the covariate age does not significantly impact the results and all within-subject effects did not reach the 5\%-level of significance. The coefficients are shown in Table $\mathbf{1 .}$

\section{Subjective Physical Symptoms}

The result of a MANCOVA with repeated measures showed no significant effect of hearing impairment for subjective physical symptoms. Also, the covariate age as well as effects of measurement time did not reach the $5 \%$-level of significance (see Table 1).

\section{Cortisol Level}

The results of an ANCOVA with repeated measures showed a significant effect for the covariate age and for hearing impairment. Furthermore, the effect time $\mathrm{x}$ hearing impairment just failed significance. The results of the analysis of covariance indicated that although age had a significant effect on the cortisol level, group differences remained significant. All other effects do not reach the $5 \%$-level of significance (see Table 1 ). The descriptive statistics are shown in Table 2. Hearing impaired employees tend to show lower cortisol levels than normal hearing employees. The effect is most pronounced for the waking cortisol level of the second day ( $\mathrm{t} 2$ ). Follow-up analyses (ANCOVAs) that were conducted for each time point, show that the effect only reaches the level of significance for this time of measurement (see Table 3). Hearing impaired employees show a significant lower waking cortisol level than normal hearing employees.

\section{DISCUSSION}

The aim of the study was to examine whether age and hearing impairment do have an impact on psychophysiological and

TABLE 2 | Descriptive statistics: cortisol level - hearing impairment groups.

\begin{tabular}{llccc}
\hline & Hearing impairment groups & $\boldsymbol{M}$ & SD & N \\
\hline Cortisol t1 [nmol//] & Normal hearing group & 2.49 & 1.39 & 30 \\
& Hearing impaired group & 2.49 & 1.92 & 21 \\
& Total & 2.49 & 1.61 & 51 \\
Cortisol t2 [nmol/I] & Normal hearing group & 24.24 & 14.79 & 30 \\
& Hearing impaired group & 19.91 & 11.19 & 21 \\
& Total & 22.46 & 13.48 & 51 \\
Cortisol t3 [nmol/I] & Normal hearing group & 2.48 & 1.02 & 30 \\
& Hearing impaired group & 2.27 & 1.31 & 21 \\
& Total & 2.40 & 1.14 & 51
\end{tabular}

TABLE 3 | Cortisol level - results of the ANCOVAs.

\begin{tabular}{lccccc}
\hline & $\boldsymbol{F}$ & $\boldsymbol{d} \boldsymbol{f}$ & $\boldsymbol{d f}_{\text {Error }}$ & $\boldsymbol{p}$ & $\boldsymbol{\eta}_{\mathbf{p}}^{\mathbf{2}}$ \\
\hline $\mathbf{t 1}$ & & & & & \\
Age & 1.31 & 1 & 48 & 0.258 & 0.027 \\
Hearing impairment & 0.25 & 1 & 48 & 0.621 & 0.005 \\
$\mathbf{t 2}$ & & & & & \\
Age & 4.68 & 1 & 48 & 0.035 & 0.089 \\
Hearing impairment & 4.00 & 1 & 48 & 0.051 & 0.077 \\
t3 & & & & & \\
Age & 2.79 & 1 & 48 & 0.101 & 0.055 \\
Hearing impairment & 1.76 & 1 & 48 & 0.192 & 0.035 \\
\hline
\end{tabular}

subjective effects of long working hours. The results show that from a subjective point of view (subjective emotional well-being, subjective evaluation of perceived recovery/fatigue, subjective physical symptoms), no significant group differences can be shown in our study. Furthermore, with one exception for the subdimension irritability of the subjective emotional well-being, the covariate age does not have a significant impact on the subjective results. Regarding the sub-dimension irritability it can be shown that irritability tends to decrease with age. However, the findings of the current study do not support the previous research results that older employees seem to have a stronger need of recovery than younger employees (e.g., Jansen et al., 2002; Kiss et al., 2008). Furthermore, the findings are contrary to previous studies which have suggested a reduced subjective emotional well-being of hearing impaired employees (Monzani et al., 2008) and a higher need of recovery after work of people with poorer than of people with better hearing status (Nachtegaal et al., 2009). A possible explanation for these results may be that hearing impaired employees may have a variety of conscious and unconscious coping strategies to cope with demanding working situations. This is an important issue for future research. Furthermore, the motivation of the participants during the study was not assessed. It could be argued that the different groups do differ in their motivation. Maybe older and/or hearing impaired participants do not have to prove themselves as strongly as others. It may be that these participants have perceived the study less demanding than others. The result that the irritability of the participants at the end of the study sessions tends to decrease with age can also be seen as indication for this. Therefore, participant's motivation should be included in future studies.

Interestingly, data of salivary cortisol reveal that the nonsignificant subjective results are not supported by the objective physiological saliva cortisol data. A significant effect of hearing impairment was shown for the cortisol level. Furthermore, the effect time $\mathrm{x}$ hearing impairment just failed significance and a significant effect for the covariate age can be reported. The results of the analyses indicated that although the covariate age had a significant effect on the cortisol level, group differences remained significant: Hearing impaired employees tend to show lower cortisol levels than normal hearing employees. The effect is most pronounced for the waking cortisol level of the second day (t2). Follow-up analyses that were conducted for each time point showed that the effect only reaches the level of significance 
for this time of measurement. Hearing impaired employees show a significant lower waking cortisol level than normal hearing employees. Following Boucsein and Backs (2000) an increase of cortisol level is an indicator for mental and emotional strain. Following these results, long working hours seem to have a psychophysiological impact on normal hearing employees. The comparison of normal hearing and hearing impaired employees shows that at least three hours of experimentally induced longer working hours result in a stronger response of the stress system of normal hearing employees in the morning of the following day. This effect differs from the expectation that the effort of a hearing impaired participant must expend in order to receive the same perceptual performance as a normal hearing employee (effortfulness hypothesis; Rabbitt, 1968; Kahneman, 1973; McCoy et al., 2005). This might also have an impact on psychophysiological reactions of the organism measured with saliva cortisol. To exclude an effect of possible confounding variables on the waking cortisol level, group differences regarding variables such as awakening time, sleep duration and perceived sleep quality were analyzed (e.g., Edwards et al., 2001). The results show that within our sample, normal hearing and hearing impaired participants do not differ significantly within these variables.

Furthermore, the idea arises that following Steptoe et al. (1998, 2000) which emphasize that job strain is able to influence the cortisol level, lower cortisol levels of hearing impaired employees compared to normal hearing employees (esp. at t2) may also be explained by different levels of job strain of the participants. Unfortunately, this variable was not included in the study but the profession of the participants was surveyed. Additionally they were asked if they have a leadership position which may also correlate with subjectively experienced job strain. Regarding the two hearing impairment groups, no significant differences can be shown concerning the professions of the participants. Also, they do not differ significantly with regard to leadership positions. Another explanation that is not proven yet is that hearing impaired employees anyway have to struggle with a lot of impairment-related difficulties during their normal working life and therefore the additional expense of some additional working hours has not that much negative influence on them at the first sight. It is therefore likely that normal hearing employees are more affected by long working hours than their hearing impaired colleagues, especially after the first day of their occurrence. Another explanation of the results may be that especially persons with mild hearing impairment, who were often part of samples with persons of working age, are able to compensate their impairment and adapt to the situation quite well. Further studies should investigate whether the effect can be confirmed for extended periods of long working hours which might be more demanding than 2 days with overtime hours.

\section{STUDY LIMITATIONS AND DIRECTIONS FOR FUTURE RESEARCH}

This study has some limitations. First, our study participants had to work long working hours on two consecutive days.
Especially regarding the non-significant subjective effects but also regarding effects on the cortisol level (see also Marchand et al., 2012), it is supposed that this singular overtime event was maybe not severe enough to make possible subjective effects of long working hours visible. Further studies should therefore address extended periods of long working hours to receive more information.

Second, we did not test our participants on "normal" working days without working overtime hours. We therefore recommend that future research shall include days without extended working hours as additional control condition. Other possibilities to enable a comparison between normal and long working hours are the inclusion of a baseline measurement of cortisol level before the sessions of additional work and/or the inclusion of a control group working normal working hours, into the study design.

One limitation of the study is that young/old comparisons in psychophysiological parameters can always be questioned, as the physiological system and the systems reactivity normally change with increasing age (Janke and Kallus, 1995).

Furthermore, from a practical point of view it would be interesting to examine possible demanding working situations in future studies that are more and more typical for a global working world, like audio-conferences during unusual working hours (e.g., late in the evening, very early in the morning) and/or in foreign languages. Another facet with practical implications is the impact of environmental conditions of the workplace like noise or lack of space or privacy like it could be found in open-plan offices. In addition, the investigation of different categories of work (e.g., professionals, white-collar workers, blue-collar workers) should be addressed in future studies.

\section{CONCLUSION}

The results of our study show no significant effects for age and hearing impairment on the intensity of subjective consequences of long working hours. But, age and hearing impairment do matter from a psychophysiological point of view. Psychophysiological responses (saliva cortisol level) on long working hours differ significantly between hearing impaired and normal hearing employees. Interestingly, the results suggest that long working hours were more demanding for normal hearing than for hearing impaired employees. Furthermore, normal hearing employees tend to show a higher waking cortisol level after 1 day with long working hours than hearing impaired employees. To uncover possible long-term effects further research is still required.

\section{ETHICS STATEMENT}

This study was carried out in accordance with the recommendations of the ethics committee of the University of Graz with written informed consent from all subjects. The study was approved by the ethics committee of the University of Graz. 


\section{AUTHOR CONTRIBUTIONS}

All authors listed have made a substantial, direct and intellectual contribution to the work, and approved it for publication.

\section{FUNDING}

This work was supported by funds of the Oesterreichische Nationalbank (OeNB) (Anniversary Fund project numbers 15025

\section{REFERENCES}

Adam, E. K., Hawkley, L. C., Kudielka, B. M., and Cacioppo, J. T. (2006). Day-today dynamics of experience-cortisol associations in a population-based sample of older adults. Proc. Natl. Acad. Sci. U.S.A. 103, 17058-17063. doi: 10.1073/ pnas.0605053103

Akerstedt, T., Fredlund, P., Gillberg, M., and Jansson, B. (2002). Work load and work hours in relation to disturbed sleep and fatigue in a large representative sample. J. Psychosom. Res. 53, 585-588. doi: 10.1016/S0022-3999(02) 00447-6

Allmer, H. (1996). Erholung und Gesundheit: Grundlagen, Ergebnisse und Maßnahmen [Recovery and Health: Foundations, Results and Measures]. Göttingen: Hogrefe.

Arlinger, S. (2003). Negative consequences of uncorrected hearing loss-a review. Int. J. Audiol. 42, 17-20. doi: 10.3109/14992020309074639

Baskent, D., Eiler, C. L., and Edwards, B. (2010). Phonemic restoration by hearingimpaired listeners with mild to moderate sensorineural hearing loss. Hear. Res. 260, 54-62. doi: 10.1016/j.heares.2009.11.007

Beswick, J., and White, J. (2003). Working Long Hours. Sheffield: Crown.

Boisard, P., Cartron, D., Gollac, M., and Valeyre, A. (2003). Time and Work: Duration of Work. Luxembourg: European Foundation for the Improvement of Living and Working Conditions.

Boucsein, W., and Backs, R. W. (2000). "Engineering psychophysiology as a discipline: historical and theoretical aspects," in Engineering Psychophysiology. Issues and Applications, eds R. W. Backs and W. Boucsein (London: Lawrence Erlbaum Associates), 3-30.

Boxtel, M. P. J., van Beijsterveldt, C. E. M., Houx, P. J. L., Anteunis, J. C., Metsemakers, J. F. M., and Jolles, J. (2000). Mild hearing impairment can reduce verbal memory performance in a healthy adult population. J. Clin. Exp. Neuropsychol. 22, 147-154. doi: 10.1076/1380-3395(200002)22:1;1-8;FT147

Buell, P., and Breslow, L. (1960). Mortality from coronary heart disease in California men who work long hours. J. Chronic Dis. 11, 615-626. doi: 10.1016/ 0021-9681(60)90060-6

Caruso, C., Hitchcock, E., Dick, R., Russo, J., and Schmit, J. (2004). Overtime and Extended Work Shifts: Recent Findings on Illnesses, Injuries, and Health Behaviors. Cincinnati: NIOSH Publications Dissemination.

Caruso, C. C. (2006). Possible broad impacts of long work hours: a review article. Ind. Health 44, 531-536. doi: 10.2486/indhealth.44.531

Dahlgren, A., Kecklund, G., and Åkerstedt, T. (2006). Overtime work and its effects on sleep, sleepiness, cortisol and blood pressure in an experimental field study. Scand. J. Work Environ. Health 32, 318-327. doi: 10.5271/sjweh.1016

Dalton, D. S., Cruickshanks, K. J., Klein, B. E. K., Klein, R., Wiley, T. L., and Nondahl, D. M. (2003). The impact of hearing loss on quality of life in older adults. Gerontologist 43, 661-668. doi: 10.1093/geront/43.5.661

Deixelberger-Fritz, D., Tischler, M., and Kallus, K. (2003). Changes in performace, mood state and workload due to energy drinks in pilots. Int. J. Appl. Aviat. Stud. 3, 195-205.

Dembe, A. E., Erickson, J. B., Delbos, R. G., and Banks, S. M. (2005). The impact of overtime and long work hours on occupational injuries and illnesses: new evidence from the United States. Occup. Environ. Med. 62, 588-597. doi: 10.1136/oem.2004.016667

Dex, S., Clark, A., and Taylor, M. (1995). Household Labour Supply. Department of Employment Research Series: Bd. 43. Colchester: University of Essex. and 16793). The authors acknowledge the financial support by the University of Graz.

\section{ACKNOWLEDGMENTS}

The authors would like to acknowledge Kerstin Eibel and the student assistants Sophie Fürstenberg, Nina Pittino, Michael Gutknecht, Janin Schröder, and Lisa Winkler, for their collaboration during the research project, and all participants who participated.

Doyle, A. (2017). Difference Between an Exempt and a Non-Exempt Employee. Resource Document. Available at: https://www.thebalance.com/exempt-and-anon-exempt-employee-2061988

Edwards, S., Evans, P., Hucklebridge, F., and Clow, A. (2001). Association between time of awakening and diurnal cortisol secretory activity. Psychoneuroendocrinology 26, 613-622. doi: 10.1016/S0306-4530(01)00015-4

Eller, N. H., Netterstrom, B., and Hansen, A. M. (2006). Psychosocial factors at home and at work and levels of salivary cortisol. Biol. Psychol. 73, 280-287. doi: 10.1016/j.biopsycho.2006.05.003

Erdmann, G., and Janke, W. (1994). Die Mehrdimensionale Körperliche Symptomliste (MKSL) [German Version of the Multidimensional Physical Symptom List]. Berlin: TU Berlin.

Eurofound (2016). Working Time Developments in the 21st Century: Work Duration and its Regulation in the EU. Luxembourg: Publications Office of the European Union.

European Parliament and Council of the European Union (2003). Directive 2003/88/EC of the European Parliament and of the Council of 4 November 2003 concerning certain aspects of the organisation of working time. Off. J. L299, L299/9-L299/19.

European Working Group on Genetics of Hearing Impairment [EUWG] (1996). Resource Document. Available at: http://audiology.unife.it/www.gendeaf.org/ hear/infoletters/Info_02.PDF

Folkard, S., and Lombardi, D. A. (2006). Modeling the impact of the components of long work hours on injuries and "accidents". Am. J. Ind. Med. 49, 953-963. doi: 10.1002/ajim.20307

Frtusova, J. B., and Phillips, N. A. (2016). The auditory-visual speech benefit on working memory in older adults with hearing impairment. Front. Psychol. 7:490. doi: 10.3389/fpsyg.2016.00490

Gablenz, P., Hoffmann, E., and Holube, I. (2017). Prävalenz von schwerhörigkeit in Nord- und Süddeutschland [prevalence of hearing loss in Northern and Southern Germany]. HNO 65, 663-670. doi: 10.1007/s00106-016-0314-8

Geurts, S. A. E., Beckers, D. G. J., Taris, T. W., Kompier, M. A. J., and Smulders, P. G. W. (2009). Worktime demands and work-family interference: does worktime control buffer the adverse effects of high demands? J. Bus. Ethics 84, 229-241. doi: 10.1007/s10551-008-9699-y

Hawkins, K., Bottone, F. G., Ozminkowski, R. J., Musich, S., Bai, M., Migliori, R. J., et al. (2012). The prevalence of hearing impairment and its burden on the quality of life among adults with Medicare Supplement Insurance. Qual. Life Res. 21, 1135-1147. doi: 10.1007/s11136-011-0028-z

Healy, A. F., Kole, J. A., Buck-Gengler, C. J., and Bourne, L. E. (2004). Effects of prolonged work on data entry speed and accuracy. J. Exp. Psychol. Appl. 10, 188-199. doi: 10.1037/1076-898X.10.3.188

Heffernan, E., Coulson, N. S., Henshaw, H., Barry, J. G., and Ferguson, M. A. (2016). Understanding the psychosocial experiences of adults with mildmoderate hearing loss: an application of Leventhal's self-regulatory model. Int. J. Audiol. 55(Suppl. 3), S3-S12. doi: 10.3109/14992027.2015.1117663

Heller, O. (1985). Hörfeldaudiometrie mit dem Verfahren der Kategorienunterteilung (KU) [Listening field audiometry by the process of categorical subdivision (KU)]. Psychol. Beiträge 27, 478-493.

Hougaard, S., and Ruf, S. (2011). EuroTrak I: a consumer survey about hearing aids in Germany, France and the UK. Hear. Rev. 18, 12-28.

Iwasaki, K., Sasaki, T., Oka, T., and Hisanaga, N. (1998). Effect of working hours on biological functions related to cardiovascular system among salesmen in 
a machinery manufacturing company. Ind. Health 36, 361-367. doi: 10.2486/ indhealth.36.361

Jahncke, H., and Halin, N. (2012). Performance, fatigue and stress in openplan offices: the effect of noise and restoration on hearing impairmed and normal hearing individuals. Noise Health 14, 260-272. doi: 10.4103/1463-1741. 102966

Janke, W., and Debus, G. (1978). Die Eigenschaftswörterliste (EWL) [German Version of the Adjective Checklist]. Göttigen: Hogrefe.

Janke, W., Debus, G., Kallus, K. W., Hüppe, M., and Schmidt-Atzert, L. (1986). Befindlichkeitsskalierung nach Kategorien und Eigenschaftswörtern (BSKE(EWL)-ak-24) [German Version of the Category Adjective Checklist]. Würzburg: Julius-Maximilian-Universität.

Janke, W., and Kallus, K. W. (1995). “"Reaktivität [Reactivity]”, in Enzyklopädie der Psychologie [Encyclopedia of Psychology], ed. M. Amelang (Göttingen: Hogrefe), $1-89$.

Jansen, N. W. H., Kant, I. J., and van den Brandt, P. (2002). Need for recovery in the working population: description and associations with fatigue and psychological distress. Int. J. Behav. Med. 9, 322-340. doi: 10.1207/ S15327558IJBM0904_03

Jennings, M. B., and Shaw, L. (2008). Impact of hearing loss in the workplace: raising questions about partnerships with professionals. Work 30, 289-295.

Kahneman, D. (1973). Attention and Effort. Upper Saddle River NJ: Prentice-Hall Inc.

Kallus, K. W. (2016). "RESTQ-Basic: the general version of the RESTQ," in The Recovery-Stress Questionnaires: User Manual, eds K. W. Kallus and M. Kellmann (Frankfurt: Pearson Assessment \& Information GmbH), 49-85.

Kallus, K. W., and Eibel, K. (2007). Die Skala Zur Wahrgenommenen Erholung (SwE) [German Version of the Scale for Perceived Recovery]. Graz: University of Graz.

Kallus, K. W., and Eibel, K. (2008). Die Skala Zur Wahrgenommenen Ermüdung (SwM) [German Version of the Scale for Perceived Fatigue]. Graz: University of Graz.

Kallus, K. W., and Erdmann, G. (1994). "Zur wechselbeziehung zwischen ausgangszustand, Belastung und Erholung [The interrelations of initial sate, stress andrecovery]," in Arbeit und Erholung. Studien zur Aktivierung, Belastung und zum Arbeits-Erholungszyklus [Work and recovery. Studies on Activation, Stress and the Work-Recovery Cycle], eds R. Wieland Eckelmann, H. Allmer, J. Otto, and K. W. Kallus (Weinheim: PVU), 46-67.

Kellmann, M., and Kallus, K. W. (2000). Der Erholungs-Belastungsfragebogen für Sportler (EBF-Sport) - Manual [The Recovery-Stress Questionnaire for Athlethes - Manual]. Frankfurt: Swets Test Service.

Kirschbaum, C. (1991). Cortisolmessung im Speichel: Eine Methode der Biologischen Psychologie [Cortisol Measurements in Saliva: A Method of Biological Psychology]. Bern: Huber.

Kiss, P., De Meester, M., and Braeckman, L. (2008). Differences between younger and older workers in the need for recovery after work. Int. Arch. Occup. Environ. Health 81, 311-320. doi: 10.1007/s00420-007-0215-y

Knauth, P. (2007). Extended work periods. Ind. Health 45, 125-136. doi: 10.2486/ indhealth.45.125

Kodz, J., Davis, S., Lain, D., Sheppard, E., Rick, J., Strebler, M., et al. (2003). Working Long Hours in the UK: A Review of the Research Literature, Analysis of Survey Data and Cross-National Organizational Case Studies. Employment Relations Research Series Nr. 16. London: Department of Trade \& Industry.

Krejcza, K. (2006). Erholungsforschung in der Therme: zur Bedeutung von kompensatorischen Erholungsmaßnahmen in Abhängigkeit vom Ausgangszustand [Recreational Research in the Thermal spa: the Importance of Compensatory Recovery Measures as a Function of the Initial State]. Graz: University of Graz.

Krenn, M., and Hermann, C. (2004). Long Working Hours in Austria. Available at: http://www.eurofound.europa.eu/ewco/2004/12/AT0412NU01.htm

Kuhn, P., and Lozano, F. (2006). The expanding workweek? understanding trends in long work hours among U.S. Men, 1979-2004. J. Lab. Econ. 26, 311-343. doi: $10.1086 / 533618$

Kunz-Ebrecht, S. R., Kirschbaum, C., Marmot, M., and Steptoe, A. (2004). Differences in cortisol awakening response on work days and weekends in women and men from the Whitehall II cohort. Psychoneuroendocrinology 29, 516-528. doi: 10.1016/S0306-4530(03)00072-6
Lemke, U., and Scherpiet, S. (2015). Oral communication in individuals with hearing impairment- considerations regarding attentional, cognitive and social resources. Front. Psychol. 6:998. doi: 10.3389/fpsyg.2015. 00998

Lin, F. R., Ferrucci, L., Metter, E. J., Yang, A., Zonderman, A. B., and Resnick, S. M. (2011). Hearing loss and cognition in the baltimore longitudinal study of aging. Neuropsychology 25, 763-770. doi: 10.1037/a0024238

Liu, Y., and Tanaka, H. (2002). Overtime work, insufficient sleep, and risk of nonfatal acute myocardial infarction in Japanese men. J. Occup. Environ. Med. 59, 447-451. doi: 10.1136/oem.59.7.447

Marchand, A., Durrand, P., and Lupien, S. (2012). Work hours and cortisol variation from non-working to working days. Int. Arch. Occup. Environ. Health 86, 553-559. doi: 10.1007/s00420-012-0788-y

Mathers, C., Smith, A., and Concha, M. (2000). Global Burden of Hearing Loss in the Year 2000. Global Burdon of Disease. Geneva: World Health Organization.

McCoy, S. L., Tun, P. A., Cox, L. C., Colangelo, M., Stewart, R. A., and Wingfield, A. (2005). Hearing loss and perceptual effort: downstream effects on older adults' memory for speech. Q. J. Exp. Psychol. Sect. A Hum. Exp. Psychol. 58, 22-33. doi: 10.1080/02724980443000151

Monzani, D., Galeazzi, G. M., Genovese, E., Marrara, A., and Martini, A. (2008). Psychological profile and social behaviour of working adults with mild or moderate hearing loss. Acta Otorhinolaryngol. Ital. 28, 61-66.

Mudar, R. A., and Husain, F. T. (2016). Neural alterations in acquired age-related hearing loss. Front. Psychol. 7:828. doi: 10.3389/fpsyg.2016.00828

Müller, P. (2011). Einsatz Älterer Menschen zur Reduktion des Fachkräftemangels: Eine Analyse in Mittelständischen Unternehmen [Use of Elderly People to Reduce Skilled Labor: An Analysis in Medium-Sized Enterprises]. Wiesbaden: Gabler.

Nachreiner, F. (2002). "Arbeitszeit und Unfallrisiko [Working time and accident risk]," in Psychologie der Arbeitssicherheit und Gesundheit Neue Welten - Alte Welten [Psychology of Occupational Safety and Health - New Worlds - Ancient Worlds], eds R. Trimpop, B. Zimolong, and A. Kalveram (Heidelberg: Asanger), $5-16$.

Nachtegaal, J., Festen, J. M., and Kramer, S. E. (2012). Hearing ability in working life and its relationship with sick leave and self-reported work productivity. Ear. Hear. 33, 94-103. doi: 10.1097/AUD.0b013e318228033e

Nachtegaal, J., Kuik, D. J., Anema, J. R., Goverts, S. T., Festen, J. M., and Kramer, S. E. (2009). Hearing status, need for recovery after work, and psychosocial work characteristics: Results from an internet-based national survey on hearing. Int. J. Audiol. 48, 684-691. doi: 10.1080/14992020902962421

National Academy on an Aging Society (1999). Hearing Loss: A Growing Problem that Affects Quality of Life. Challenges of the 21st Century: Chronic and Disabling Conditions. Washington, DC: National Academy on an Aging Society, 1-6.

Neijenhuis, K., Tschur, H., and Snik, A. (2004). The effect of mild hearing impairment on auditory processing tests. J. Am. Acad. Audiol. 15, 6-16. doi: $10.3766 /$ jaaa.15.1.3

Park, J., Kim, Y., Cho, Y., Woo, K., Chung, K., Sasaki, T., et al. (2001). Regular overtime and cardiovascular function. Ind. Health 39, 244-249. doi: 10.2486/ indhealth.39.244

Pearman, A., Friedman, L., Brooks, J. O., and Yesavage, J. A. (2000). Hearing impairment and serial word recall in older adults. Exp. Aging Res. 26, 383-391. doi: 10.1080/036107300750015769

Persson, R., Ørbæk, P., Ursin, H., Kecklund, G., Österberg, K., and Åkerstedt, T. (2003). Effects of the implementation of an 84-hour workweek on neurobehavioral test performance and cortisol responsiveness during testing. Scand. J. Work Environ. Health 29, 261-269. doi: 10.5271/ sjweh.730

Pruessner, J. C., Wolf, O. T., Hellhammer, D. H., Buske-Kirschbaum, A., von Auer, K., and Jobst, S. (1997). Free cortisol levels after awakening: a reliable biological marker for the assessment of adrenocortical activity. Life Sci. 61, 2539-2549. doi: 10.1016/S0024-3205(97)01008-4

Rabbitt, P. M. A. (1968). Channel-capacity, intelligibility and immediate memory. Q. J. Exp. Psychol. 20, 241-248. doi: 10.1080/14640746808400158

Raediker, B., Janßen, D., Schomann, C., and Nachreiner, F. (2006). Extended working hours and health. Chronobiol. Int. 23, 1305-1316. doi: 10.1080/ 07420520601096245

Rau, R., and Triemer, A. (2004). Overtime in relation to blood pressure and mood during work, leisure and night time. Soc. Indic. Res. 67, 51-73. doi: 10.1023/B: SOCI.0000007334.20490.52 
Rönnberg, J., Danielsson, H., Rudner, M., Arlinger, S., Sternäng, O., Wahlin, Å., et al. (2011). Hearing loss is negatively related to episodic and semantic longterm memory but not to short-term memory. J. Speech Lang. Hear. Res. 54, 705-726. doi: 10.1044/1092-4388(2010/09-0088)

Rudner, M., Rönnberg, J., and Lunner, T. (2011). Working memory supports listening in noise for persons with hearing impairment. J. Am. Acad. Audiol. 22, 156-167. doi: 10.3766/jaaa.22.3.4

Scarincia, N., Worralla, L., and Hicksona, L. (2009). The effect of hearing impairment in older people on the spouse: development and psychometric testing of The Significant Other Scale for Hearing Disability (SOS-HEAR). Int. J. Audiol. 48, 671-683. doi: 10.1080/14992020902998409

Scherer, M. J., and Frisina, D. R. (1998). Characteristics associated with marginal hearing loss and subjective well-being among a sample of older adults. J. Rehabil. Res. Dev. 35, 420-426.

Selye, H. (1936). A Syndrome produced by diverse nocuous agents. Nature 138:32. doi: 10.1038/138032a0

Sonnentag, S., Binnewies, C., and Mojza, E. J. (2008). Did you have a nice evening? A day-level study on recovery experience, sleep, and affect. J. Appl. Psychol. 93, 674-684. doi: 10.1037/0021-9010.93.3.674

Sonnentag, S., and Zijlstra, F. R. H. (2006). Job characteristics and off-job activities as predictors of need for recovery, well-being, and fatigue. J. Appl. Psychol. 91, 330-350. doi: 10.1037/0021-9010.91.2.330

Sparks, K., Cooper, C., Freid, Y., and Shiroam, A. (1997). The effects of hours of work on health: a meta-analytic review. J. Occup. Organ. Psychol. 70, 391-408. doi: 10.1111/j.2044-8325.1997.tb00656.x

Spurgeon, A., Harrington, J. M., and Cooper, C. L. (1997). Health and safety problems associated with long working hours: a review of the current position. Occup. Environ. Med. 54, 367-375. doi: 10.1136/oem.54. 6.367

Statistik Austria (2014). Altersstruktur der Erwerbspersonen 2012, 2030 und 2050 nach Bundesländern (laut Hauptszenario) [Age structure of the Employees in 2012, 2030 and 2050 by Federal Government (According to the Main Scenario)]. Wien: Statistik Austria.

Steptoe, A., Cropley, M., Griffith, J., and Kirschbaum, C. (2000). Job strain and anger expression predict early morning elevations in salivary cortisol. Psychosom. Med. 62, 286-292. doi: 10.1097/00006842-200003000-00022

Steptoe, A., Wardle, J., Lipsey, Z., Mills, R., Oliver, G., Jarvis, M., et al. (1998). A longitudinal study of work load and variations in psychological well-being, cortisol, smoking, and alcohol consumption. Ann. Behav. Med. 20, 84-91. doi: 10.1007/BF02884453

Su, T.-C., Lin, L.-Y., Baker, D., Schnall, P. L., Chen, M.-F., Hwang, W.-C., et al. (2008). Elevated blood pressure, decreased heart rate variability and incomplete blood pressure recovery after a 12-hour night shift work. J. Occup. Health 50, 380-386. doi: 10.1539/joh.L7056
Trimpop, R., Kirkcaldy, B., Athanasou, J., and Cooper, C. (2000). Individual differences in working hours, work perceptions and accident rates in veterinary surgeries. Work Stress 14, 181-188. doi: 10.1080/026783700750051685

Trinkoff, A. M., Le, R., Geiger-Brown, J., Lipscomb, J., and Lang, G. (2006). Longitudinal relationship of work hours, mandatory overtime, and on-call to musculoskeletal problems in nurses. Am. J. Ind. Med. 49, 964-971. doi: 10.1002/ ajim. 20330

U.S. Department of Labor: Wage and Hour Division (2008). Fact Sheet \#23: Overtime Pay Requirements of the FLSA. Resource Document. Available at: https://www.dol.gov/whd/regs/compliance/whdfs23.pdf

U.S. Department of Labor: Wage and Hour Division. (2012). Basic Information. Resource Document. Available at: https://www.dol.gov/whd/regs/compliance/ whd_fs.pdf

Uehata, T. (1991). Long working hours and occupational stress-related cardiovascular attacks among middle-aged workers in Japan. J. Hum. Erg. 20, 147-153.

Violanti, J. M., Burchfield, C. M., Hartley, T. A., Andrew, M. E., and Vila, B. J. (2009). A typical work hours and metabolic syndrome among police officers. Archiv. Environ. Occup. Health 64, 194-201. doi: 10.1080/19338240903241259

World Health Organization [WHO] (1993). Aging, and Working Capacity. Geneva: World Health Organization.

World Health Organization [WHO] (2015a). Deafness and Hearing Loss. Fact Sheet $N^{\circ} 300$. Resource Document. Available at: http://www.who.int/mediacentre/ factsheets/fs300/en/

World Health Organization [WHO] (2015b). Hearing Loss Due to Recreational Exposure to Loud Sounds. A Review. Resource Document. Available at: http://apps.who.int/iris/bitstream/10665/154589/1/9789241508513_eng.pdf

Wingfield, A., Amichetti, N. M., and Lash, A. (2015). Cognitive aging and hearing acuity: modeling spoken language comprehension. Front. Psychol. 6:684. doi: $10.3389 /$ fpsyg.2015.00684

Wust, S., Wolf, J., Hellhammer, D. H., Federenko, I., Schommer, N., and Kirschbaum, C. (2000). The cortisol awakening response - normal values and confounds. Noise Health 2, 79-88.

Conflict of Interest Statement: The authors declare that the research was conducted in the absence of any commercial or financial relationships that could be construed as a potential conflict of interest.

Copyright $\odot 2018$ Wagner-Hartl and Kallus. This is an open-access article distributed under the terms of the Creative Commons Attribution License (CC BY). The use, distribution or reproduction in other forums is permitted, provided the original author(s) or licensor are credited and that the original publication in this journal is cited, in accordance with accepted academic practice. No use, distribution or reproduction is permitted which does not comply with these terms. 